\title{
Haemodilution and total body perfusion
}

\author{
DOUGLAS COHEN, GRAHAM FISK, D. C. GENGOS, \\ A N D B A B A R A A TES 1
}

\begin{abstract}
From the Adolph Basser Institute of Cardiology. The Royal Alexandra Hospital for Children, Sydney, Australia
\end{abstract}

During the last 10 years the technique of cardiopulmonary by-pass has been developed to enable intracardiac surgery to be carried out in a deliberate and unhurried manner for the correction of a variety of congenital and acquired cardiac defects. Though it is realized that there are certain dangers inherent in perfusion itself, accumulated laboratory and clinical experience has gradually reduced these to an acceptable minimum. During the past few years we have seen a progressive simplification of the apparatus used for total body perfusion in an attempt to make the whole procedure less elaborate and time-consuming and, if necessary, suitable for use at relatively short notice.

One of the problems that has had to be overcome to enable this aim to be achieved has been a reduction in the amount of fresh heparinized blood originally required for the priming of the apparatus. Initially, heparinized blood freshly collected on the morning of operation was used. Because of the difficulties and delays that occurred, blood was collected on the afternoon preceding surgery and was stored overnight at a temperature of $4^{\circ} \mathrm{C}$. This has not apparently produced any adverse effects. Some centres were using older blood collected in Edglucate solution and reconstituted immediately before use, also apparently without ill-effects.

More recently, varying degrees of haemodilution have been used for cardiopulmonary by-pass (Greer, Carey, and Zuhdi, 1962 ; Cooley, Beall, and Grondin, 1962 ; DeWall, Lillehei, and Sellers, 1962). Some units use no blood at all for priming, and others reduce the amount.

A variety of clear perfusates have been employed, such as $5 \%$ glucose in distilled water, with or without the addition of low molecular weight dextran, and $\mathrm{N} / 4$ glucose saline with serum albumin added (Long, Sanchez, Varco, and Lillehei, 1961). Although some centres have continued to use a normothermic perfusion, the majority rely upon some degree of hypothermia. ${ }^{1}$ Supported by a grant from the National Heart Foundation.
Haemodilution has been developed for two reasons. First, the large amount of homologous blood required to prime the heart-lung machine was often expensive and difficult to obtain, especially at short notice. Secondly, a number of adverse physiological changes have been attributed to the use of large amounts of homologous blood (Gadboys, Slonim, and Litwak, 1962). As experience with haemodilution has been accumulated, it appears that there are certain other advantages in its use. Evidence suggests that the reduction in blood viscosity, which is achieved by haemodilution, results in a better perfusion at a capillary level. There is also less tendency to sludging of the red cells when the circulation is slowed or arrested for any reason. Protagonists of this technique maintain that the post-operative course of these patients is smoother and that their renal function is better. Using less homologous blood reduces blood damage during perfusion and the risk of homologous serum jaundice.

Haemodilution has been employed at the Royal Alexandra Hospital for Children since January 1963 in our last 50 perfusions. We feel that haemodilution has improved the standard of perfusion. The purpose of this preliminary report is to present the results in the first 10 uncomplicated cases of septal defects perfused with diluted blood, compared with 10 similar cases in our initial series in which fresh whole blood was used for priming the heart-lung machine. These 10 cases were prepared as a pilot study before continuing to use haemodilution. Initially, it was our practice to prime the heart-lung machine with whole blood freshly collected on the morning of operation. In the middle of 1962 we began to use blood collected on the previous afternoon, since this was already accepted practice in many overseas centres. This was not associated with any apparent adverse effects and was a more convenient arrangement both for the Red Cross Blood Transfusion Service and for ourselves. Since the beginning of 1963 we have continued to use blood collected the afternoon before and 
stored overnight at $4^{\circ} \mathrm{C}$, but this has been diluted as set out below.

\section{PERFUSION TECHNIQUE}

Perfusion was carried out with the Ebsray R.A.H.C. heart-lung machine (Cohen, Hercus, and Ebsary. 1960). The pump was of the rotary type with springloaded rollers, just occlusive to $300 \mathrm{~mm}$. of mercury. A rotating disc oxygenator was used, a 15-in. oxygenator being employed for estimated flow rates up to 2 litres per minute and a 21 -in. oxygenator for estimated flows in excess of this. Blood was returned to the machine from the right atrium by gravity drainage, the venous reservoir being $10 \mathrm{in}$. lower than the right atrium. A clamp on the venous line was adjusted to maintain the venous pressure at the preperfusion level. Blood was returned to the body via the external iliac artery; the largest sized cannula that would fit into the artery was used. No silicone or anti-foaming agent was used in any part of the equipment. The machine was primed with heparinized blood collected on the afternoon before surgery. Blood was collected into $500-\mathrm{ml}$. glass bottles containing 2,500 units of heparin. The bottles were then stored at $4^{\circ} \mathrm{C}$. until the morning of operation. When the 15-in. oxygenator was used. the machine was primed with $1,500 \mathrm{ml}$. of heparinized blood, $1,000 \mathrm{ml}$. of $\mathrm{N} / 4$ glucose saline, and $200 \mathrm{ml}$. of $25 \%$ serum albumin. When the 21-in. oxygenator was used, an additional $500 \mathrm{ml}$. of blood was used. The body temperature was reduced to $25-30^{\circ} \mathrm{C}$. during perfusion, and the patient was rewarmed to $36^{\circ} \mathrm{C}$. before the by-pass was discontinued. Intravenous heparin was given in a dosage of $3 \mathrm{mg} . / \mathrm{kg}$.

The patients were perfused at an estimated flow rate of $2.41 . / \mathrm{m}^{2}$ of body surface $/ \mathrm{min}$. No citrated blood was used until after the termination of by-pass ; any replacement needed before or during perfusion was effected from the machine. At the end of perfusion the patient was transfused from the machine until the heart was well filled, there was a satisfactory peripheral pulse and arterial blood-pressure, and venous pressure was approximately $20 \mathrm{~mm}$. of mercury. Further small transfusions were given from the machine during closure of the chest to replace any continuing losses. After removal of the arterial cannula, heparin was neutralized with polybrene in a dosage of $1.5 \mathrm{mg}$. of polybrene per $\mathrm{mg}$. of heparin.

\section{BIOCHEMICAL ESTIMATIONS}

Blood $p \mathrm{H}, \mathrm{PcO}_{2}$, base excess, and standard bicarbonate were measured using the E.I.L.-Robertson micro $\mathrm{PCO}_{2}$ system (Robinson and Utting, 1961) attached to an E.I.L. model 33B $p \mathrm{H}$ meter, according to the method of Astrup (1956). and using the nomogram of Siggaard Andersen and Engel (1960). Oxygen saturation and haemoglobin were determined colorimetrically with a Unicam SP 600 spectrophotometer. Estimations were carried out on the arterial blood before by-pass, on a sample from the machinepriming mixture before by-pass, at 15 -minute intervals during the by-pass procedure, and on a venous sample obtained two to three hours after the patient had been returned to the recovery ward. Further postoperative sampling was only undertaken if indicated by the patient's condition. Complete clotting studies were carried out pre-operatively and were normal in every case. These included the kaolin clotting time, bleeding time, clot retraction, prothrombin index, and prothrombin activity. The clotting times were measured in plain glass test tubes, according to the method described by Lee White, 10 minutes after the administration of polybrene.

In addition to the above biochemical estimations, we measured the blood lost at operation and on the first three post-operative days, and the urinary output on the day of operation and on the first and second post-operative days.

\section{DISCUSSION}

The first 10 patients with septal defects submitted to by-pass using the haemodilution technique were compared with 10 patients with septal defects selected from the previous group, in whom fresh whole blood collected on the morning of operation had been used and who had had an uninterrupted post-operative course free from complications and with complete recovery. The 'diluted' group consisted of five patients with secundum atrial septal defects and five with ventricular septal defects. The 'undiluted' group contained six patients with atrial septal defects, three with ventricular septal defects, and one patient with an atrial septal defect and a ventricular septal defect. The age, weight, perfusion time, and surface area of the patients in each group are set out in Table I. It can be seen that the patients in the diluted group were slightly younger but that the perfusion time is comparable in each series. A comparison of the acid-base balance of the two groups is rather difficult, as the $p \mathrm{H}$ was the only result obtained from the first group of patients and the state of the acid-base equilibrium cannot be accurately deduced from this figure alone. However, studying the three-hour post-operative $p \mathrm{Hs}$ from each group, it seems probable that there was a significantly greater degree of post-operative acidosis in the undiluted group with a mean arterial $p \mathrm{H}$ of 7.24 compared with a mean venous $p \mathrm{H}$ of 7.26 in the diluted group. In the second group, where complete results were obtained, it can be seen that immediately before perfusion 
TAB LE I

COMPARISON OF 10 PATIENTS SUBMITTED TO BY-PASS USING THE HAEMODILUTION TECHNIOUE WITH 10 PATIENTS RECEIVING FRESH WHOLE BLOOD

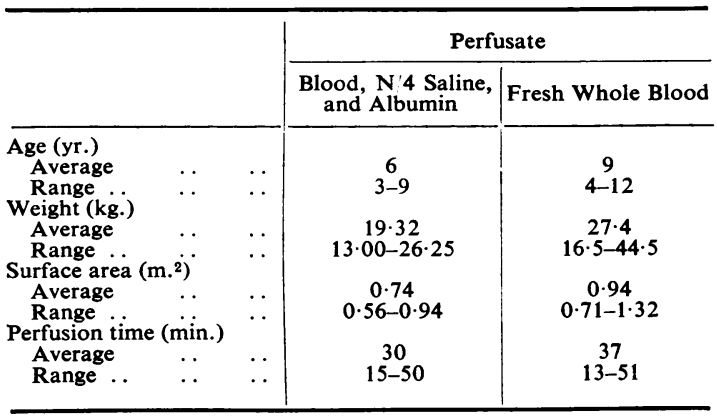

there was generally no metabolic imbalance (base excess of $-1 \mathrm{mEq} / \mathrm{l}$.) but a mild respiratory alkalosis $\left(\mathrm{PCO}_{2}\right.$ of $26 \mathrm{~mm}$. $\left.\mathrm{Hg}\right)$.

At the end of perfusion there was a significant metabolic acidosis (base excess of $-8 \mathrm{mEq} / 1$.) plus a respiratory alkalosis $\left(\mathrm{PCO}_{2}\right.$ of $19 \mathrm{~mm}$. $\left.\mathrm{Hg}\right)$ resulting in a normal $p H(7 \cdot 43)$. Post-operatively, there was a mild metabolic acidosis (base excess $-5 \mathrm{mEq} / \mathrm{l}$.) with normal respiratory figures $\left(\mathrm{PCO}_{2}\right.$ of $49 \mathrm{~mm}$. $\left.\mathrm{Hg}\right)$. The full results can be seen in Table II. It will be noted that the postoperative results in the diluted group were obtained from central venous blood. There are errors in this technique due to the greater buffering power of oxyhaemoglobin. It was found that unless the blood was grossly desaturated the errors were slight and apply only to the buffer base and $\mathrm{PCO}_{2}$ figures. Haemodilution did not

T ABLE I I

BIOCHEMICAL STUDIES

\begin{tabular}{|c|c|c|c|c|}
\hline & \multicolumn{4}{|c|}{ Perfusate } \\
\hline & \multicolumn{2}{|c|}{$\begin{array}{c}\text { Blood, N/4 Saline, } \\
\text { and Albumin }\end{array}$} & \multicolumn{2}{|c|}{$\begin{array}{c}\text { Fresh } \\
\text { Whole Blood }\end{array}$} \\
\hline & Mean & Range & Mean & Range \\
\hline 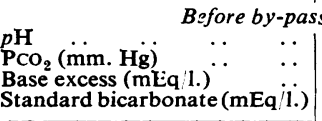 & $\mid \begin{array}{c}7 \cdot 50 \\
26 \\
-1 \\
23\end{array}$ & $\begin{array}{c}\text { rial sample } \\
7 \cdot 42-7 \cdot 57 \\
19-38 \\
+2 \text { to }-5 \\
21-25\end{array}$ & $7 \cdot 44$ & $7 \cdot 32-7 \cdot 56$ \\
\hline 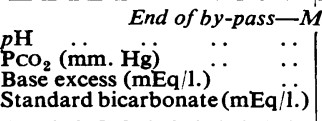 & \begin{tabular}{|} 
achine \\
$7 \cdot 43$ \\
19 \\
-8 \\
17
\end{tabular} & $\begin{array}{c}\text { sample (arter } \\
7 \cdot 38-7 \cdot 50 \\
16-22 \\
-3 \text { to }-12 \\
15-21\end{array}$ & $\begin{array}{l}\text { rial) } \\
7 \cdot 37\end{array}$ & $7 \cdot 26-7 \cdot 48$ \\
\hline 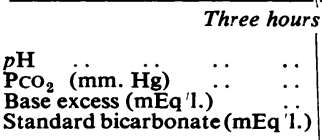 & $\begin{array}{l}\text { post-o } \\
\text { Venou } \\
7 \cdot 26 \\
49 \\
-5 \\
20\end{array}$ & $\begin{array}{l}\text { eratively } \\
\text { is Sample } \\
7 \cdot 20-7 \cdot 34 \\
43-55 \\
-2 \text { to }-8 \\
18-22\end{array}$ & $\begin{array}{l}\text { Arteri } \\
\mathbf{7 \cdot 2 4}\end{array}$ & $\begin{array}{l}\text { al Sample } \\
7 \cdot 19-7 \cdot 30\end{array}$ \\
\hline
\end{tabular}

affect the ability of the Ebsray R.A.H.C. heartlung machine to produce a satisfactory oxygen saturation at all times (Table III). Subsequent to this series, the oxygen flow through the heartlung machine has been reduced progressively from 6 litres per minute to as low as 1.5 litres per minute, as it was found that this lessened the

T ABLE II I

OXYGEN SATURATION WITH A PERFUSATE OF BLOOD, N/4 SALINE, AND ALBUMIN

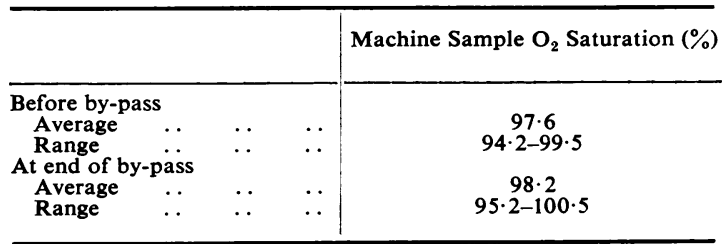

degree of respiratory alkalosis during perfusion. Oxygenation of the blood appears to be adequate at this low flow rate, and the $\mathrm{PCO}_{2}$ figure could be maintained within the normal range. Higher flow rates caused a washing out of $\mathrm{CO}_{2}$ from the blood in the machine. The clotting studies do not suggest interference with blood coagulation, the mean figure being in the normal range (Table IV). Table $\mathrm{V}$ shows the operative and post-operative blood loss in the two groups and indicates that haemodilution was not associated with an increased tendency to bleeding either during or

TABLE IV

CLOTTING TIMES

\begin{tabular}{|c|c|c|c|}
\hline \multirow{2}{*}{\multicolumn{2}{|c|}{ Mean Clotting Time }} & \multicolumn{2}{|c|}{ Perfusate } \\
\hline & & $\begin{array}{l}\text { Blood, N/4 Saline, } \\
\text { and Albumin }\end{array}$ & $\begin{array}{c}\text { Fresh } \\
\text { Whole Blood }\end{array}$ \\
\hline $\begin{array}{l}\text { Average } \\
\text { Range }\end{array}$ & 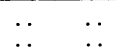 & $\stackrel{9}{7-12}$ & ${ }^{7}-10$ \\
\hline
\end{tabular}

TABLE V

BLOOD LOSS

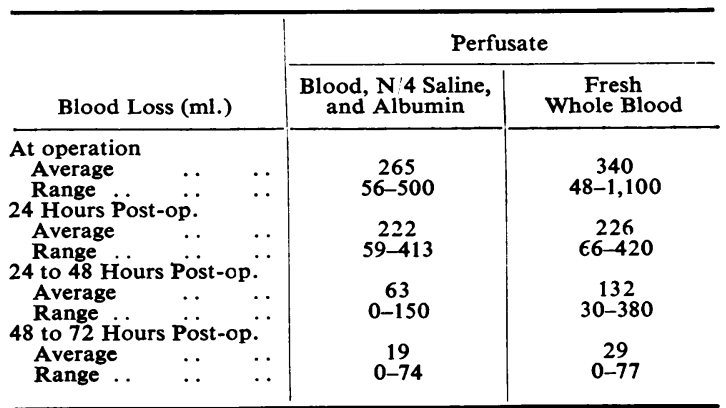


TABLE VI

URINARY OUTPUT

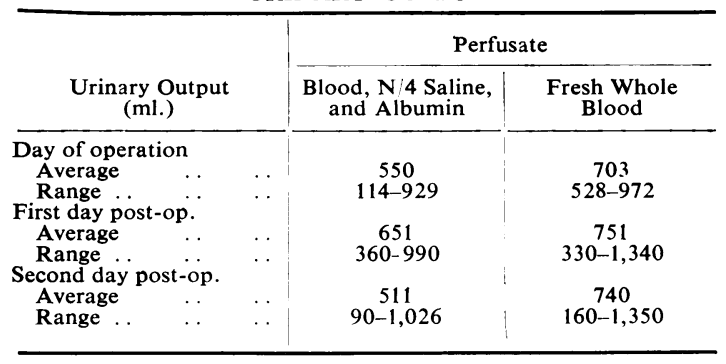

after operation. The urinary output is shown in Table VI, and, making allowance for the age difference between the two groups, the figures are comparable and indicate that haemodilution does not impose an excessive water load on these children.

Haemodilution figures are available for the diluted perfusate at the end of by-pass and three hours post-operatively and show, as one would expect, some reduction in the haemoglobin of the perfusate which, however, has returned to normal figures three hours post-operatively (Table VII).

These comparative studies and our subsequent experience in a further 40 cases have indicated that there are no deleterious effects associated

TABLE VII

HAEMOGLOBIN VALUES WITH A PERFUSATE OF BLOOD, N 4 SALINE, AND ALBUMIN

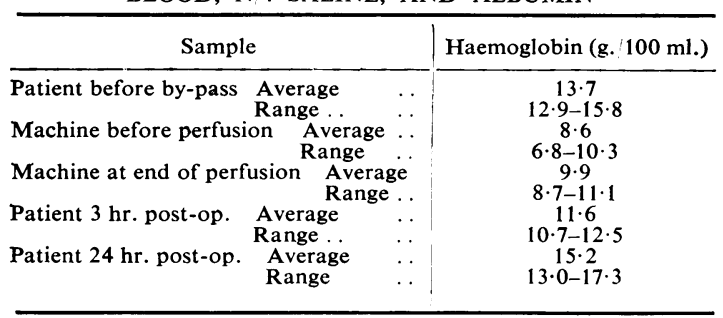

with this degree of haemodilution, and that there may be real advantages. The fact that blood isp collected on the afternoon before surgery and that relatively small quantities are required has eliminated some of the problems associated with ${ }^{\text {s }}$ whole body perfusion and has helped to bring $i \vec{p}$ more into line with other major procedures.

\section{SUMMARY}

A technique of whole body perfusion with haemo dilution is described using the Ebsray R.A.H.C. heart-lung machine.

The results obtained in the first 10 patients are compared with those of a similar group of patients in whom fresh whole blood was used ass the perfusate.

This study was made possible by a grant supplie⿳亠丷厂 by the National Heart Foundation to provide biochemical assistance.

\section{REFERENCES}

Astrup, P. (1956). A simple electrometric technique for the determo ination of carbon dioxide tension in blood and plasma, tota content of carbon dioxide in plasma, and bicarbonate content im "separated plasma" at a fixed carbon dioxide tension $(40 \mathrm{~mm} \overline{\bar{\sigma}}$ Hg). Scand. J. clin. Lab. Invest., 8, 33.

Cohen, D. H., Hercus, V. M., and Ebsary, V. R. (1960). The Roy Alexandra Hospital for Children heart-lung machine. Mec $D$ J. Aust., 2, 734

Cooley, D. A., Beall, A. C., and Grondin, P. (1962). Open-hea operations with disposable oxygenators, 5 per cent dextrose prime

operations with disposable oxygenators, 5 per cent dextrose prime
and normothermia. Surgery, 52,713 .

eWall, R. A., Lillehei, R. C., and Sellers, R. D. (1962). Hemodilution perfusions for open-heart surgery. New Er.gl. J. Med., 266 1078 .

Gadboys, H. L., Slonim, R., and Litwak, R. S. (1962). Homologousblood syndrome: 1. Preliminary observations on its relationship to clinical cardiopulmonary bypass. Ann. Surg. 156, 793.

Greer, A. E., Carey, J. M., and Zuhdi, N. (1962). Hemodilutio principle of hypothermia perfusion. A concept obviating blood priming. J. thorac. Surg., 43, 640 .

Long, D. M., Sanchez, L., Varco, R. L., and Lillehei, C. W. (1961) The use of low molecular weight dextran and serum albumin plasma expanders in extracorporeal circulation. Surgery, 50, 12

Robinson, J. S., and Utting, J. E. (1961). A simple interpolatio method for the estimation of $\mathrm{PCO}_{2}$ in whole blood. Brit. I method for the

Siggaard Andersen, O., and Engel, K. (1960). A new acid-base nomogram. An improved method for the calculation of the relevant blood acid-base data. Scand. J. clin. Lab. Invest., 12, 177 